\title{
A incidência da mídia na primeira seleção do controle social.
}

PAULO ROBERTO BATISTA ${ }^{1}$

\section{INTRODUÇÃO}

"Entende-se como controle social o conjunto de mecanismos e sanções sociais que visam a submissão do homem aos modelos e normas de convívio comunitário" 2. Nesse sentido, surgem mecanismo de controle que buscam garantir um comportamento jurídico e socialmente ajustado para o momento contemporâneo a conduta.

Com efeito, o controle é feito por intermédio das agências de controle que podem ser formais ou informais. De um lado o controle social informal3, que se reflete nos órgãos da sociedade civil: família, escola, ciclo profissional, opinião pública, clubes de Serviço, igrejas etc. De outro lado, destaca-se o controle social formal4, representado pelas instâncias políticas do Estado, isto é, a Polícia ( $1^{a}$ seleção), o Ministério Público ( $2^{\mathrm{a}}$ seleção), a Justiça ( $3^{a}$ seleção), as Forças Armadas, a Administração Penitenciária etc.

O Presente texto se propõe a fazer considerações acerca da primeira seleção do controle social formal: a polícia judiciária, assim como a mídia pode incidir nesse trabalho.

\section{PRIMEIRA SELEÇÃO}

\footnotetext{
${ }^{1}$ Servidor Público. Bacharel em Direito e Graduado em Gestão e Educação para o Trânsito. Pósgraduado em Ciências do Trânsito. Especialista em Ciências do Trânsito; Políticas Públicas do Trânsito; Segurança Pública; Direito Penal e Processo Penal.

2 (Shecaira, 2008).

${ }^{3}$ CRIMINOLOGIA NO BRASIL_HISTORI - Tangerino, Davi,Shecaira, Sergio

${ }^{4}$ CRIMINOLOGIA NO BRASIL_HISTORI - Tangerino, Davi,Shecaira, Sergio
} 
Quando um crime é cometido, nasce para o estado o direito de punir. Todavia, tal ius puniendi em desfavor do criminoso deve ser precedido do devido processo legal. Quando a ocorrência de um suposto crime é comunicada a autoridade policial essa faz um juízo de adequação a fim de verificar se o controle social será feito por intermédio do direito penal ou se por outro ramo do direito.

Em apertada síntese, é observar se o fato é ou não é um relevante penal. A partir desse momento promoverá os procedimentos necessários para a apuração da autoria e materialidade do suposto delito.

Fala-se em primeira seleção do controle social formal em face da atuação de seus órgãos de repressão jurídica, isto é, da atuação da polícia judiciária. O ius puniendi não pode ser exercitado de forma atrabiliária. Mas em atenção aos direitos e garantias fundamentais.

A premissa da monopolização da jurisdição e a finalidade de realização do bem comum, com a indispensável necessidade da garantia da ordem pública, exigem tal comportamento estatal, pois o direito existe exatamente para manter harmonia social. ${ }^{5}$ Nesse sentido assevera Frederico Marques:

\begin{abstract}
"O Estado, quando pratica atos de investigação, após a prática de um fato delituoso, está exercendo seu poder de polícia. A investigação não passa do exercício do poder cautelar que o Estado exerce, através da polícia, na luta contra o crime, para preparar a ação penal e impedir que se percam os elementos de convicção sobre o delito cometido" 6
\end{abstract}

No Brasil, a polícia civil prepara a ação penal, não apenas praticando os atos essenciais da investigação, mas também organizando uma instrução provisória a que se dá o nome de inquérito policial. Além de arbitrar a fiança para os crimes de até quatro anos de pena o delegado de polícia estabelece aí a primeira seleção de controle social.

\title{
III. A MÍDIA AMIGA E A MÍDIA INIMIGA
}

Uma operação policial bem-sucedida, a prisão de um traficante contumaz ou a elucidação de um homicídio de repercussão na comunidade local, naturalmente despertam o interesse da mídia. A divulgação desses fatos, através de rádio, jornal, tv ou internet, oferece destaque à coorporação que executou, não raras vezes concedendo momentos de fama e até certo heroísmo aos policiais responsáveis pela investigação, fomentando vaidades, impulsionando carreiras profissionais, além de promover também a própria imagem dos governantes e das autoridades da área da segurança pública.

Estamos falando da "mídia amiga", aquela sempre bem-vinda, cujos integrantes são homenageados, eventualmente, em solenidades das instituições. A Polícia Civil do RS, por exemplo, possui em sua estrutura uma DCS (divisão de comunicação social), vinculada diretamente à chefia de polícia, a qual é responsável em promover o

\footnotetext{
${ }^{5}$ CRIMINOLOGIA NO BRASIL_HISTORI - Tangerino, Davi,Shecaira, Sergio

${ }^{6}$ CRIMINOLOGIA NO BRASIL_HISTORI - Tangerino, Davi,Shecaira, Sergio
} 
marketing da instituição. A DCS acompanha as principais ações e operações policiais, divulgando áudio e imagens aos órgãos de imprensa, organizando entrevistas coletivas, participando de ações sociais sempre voltadas à visibilidade e à promoção da marca Polícia Civil.

Neste contexto, a Polícia Civil do estado do RS acompanha os indicadores de sua imagem, por meio de citações positivas, negativas ou neutras que lhe são atribuídas, diariamente, na mídia espontânea, segundo mostra o quadro comparativo EM ANEXO.

Compreensível que, diante de um quadro atual de insegurança, o clamor popular, impulsionado pela mídia e seu discurso punitivo populista, tende a querer soluções rápidas e imediatas para arrefecer a onda de violência. Exige-se dos governantes, quase milagrosamente, a imediata solução para esse problema. Assim, divulgação de operações policiais e as prisões efetuadas, sem dúvida, vêm ao encontro desta necessidade resposta sociedade.

A espetacularização da violência e o sensacionalismo por parte da imprensa, atua no sentido de proliferar a ideia de punitivismo e a necessidade, cada vez maior, da utilização do direito penal como única forma de solução para a questão da violência e da criminalidade.

Raramente encontra-se destacadas na mídia discussões e abordagens menos rasas sobre as causas da criminalidade violenta. Pouca frequência e menor destaque ainda se observa em torno da busca de soluções, a médio e longo prazo, como uma nova política pública de drogas, a principal causa dos problemas da violência urbana.

Tudo parece que tem que ser às pressas. A sociedade exige a prisão de criminosos, as polícias prendem a cada dia um maior número de pessoas, os presídios esgotam a capacidade de abrigar tantos presos. A mídia exibe este quadro, em seus noticiários, diariamente, porém, ao mesmo tempo e paradoxalmente, a sociedade continua sentindo-se insegura.

Por outro lado, no sentido contrário, quando a mídia exerce o seu papel de controle social e passa à fiscalização das ações policiais, como nas situações em que vem à tona denúncias de abusos, truculência, corrupção policial, investigações malconduzidas, aqueles atingidos com as opiniões negativas e matérias jornalísticas desabonatórias, contrariados, tornam-se críticos da mesma imprensa que, outrora, elevou-os ao patamar de "quase heróis". É o que podemos definir como "imprensa inimiga", a imprensa que persegue, que não compreende, que é vista como injusta com a polícia, logo com a polícia, instituição que tanto se sacrifica para defender a sociedade.

A mídia também se mostra inimiga quando promove uma abordagem sensacionalista. Muitas vezes promove o medo da sociedade. Essa, por essa razão passa a não ocupar os espaços públicos. Ocorre então um desserviço. 


\section{CONCLUSÃO}

É inquestionável concluir que em numa sociedade democrática a deve ser livre de qualquer juízo prévio que possa levar a censura como bem preleciona o Pacto de São José da Costa Rica. As concessionárias de rádio e televisão, nas respectivas programações devem cumprir o seu papel previsto na constitucional do Estado brasileiro. Nesse sentido, devem os programas da mídia voltar-se para o respeito aos valores éticos da pessoa humana e da família (art. 221, IV, da CF). ${ }^{7}$

Desta forma a imprensa deve cumprir o seu papel de informar sem ser parcial. A mídia não precisa ser boa, nem precisa ser ruim para as agências de controle de primeira seleção. Nem tampouco ser sensacionalista ao ponto de fomentar a TEORIA DO MEDO. Mas instrumentalizar a Liberdade de pensamento e de expressão.

ANEXO

${ }^{7}$ Nestor Sampaio Penteado Filho - Manual Esquematico de Criminologia - 2012 


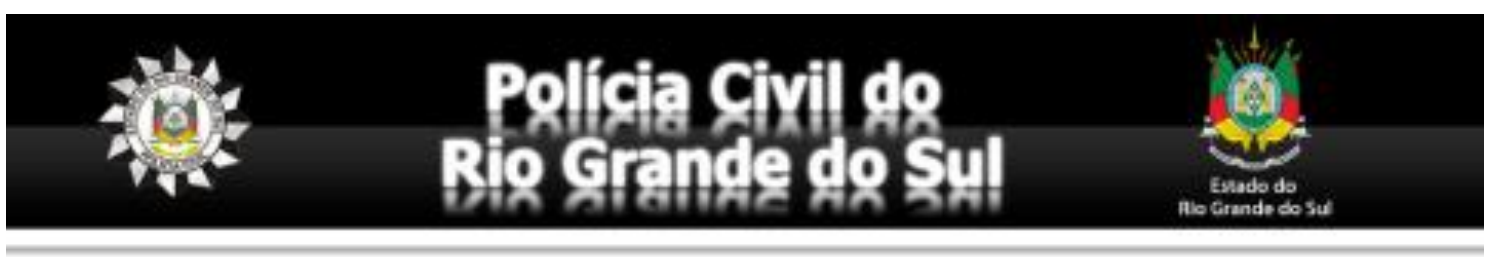

\section{IMAGEM INSTITUCIONAL}

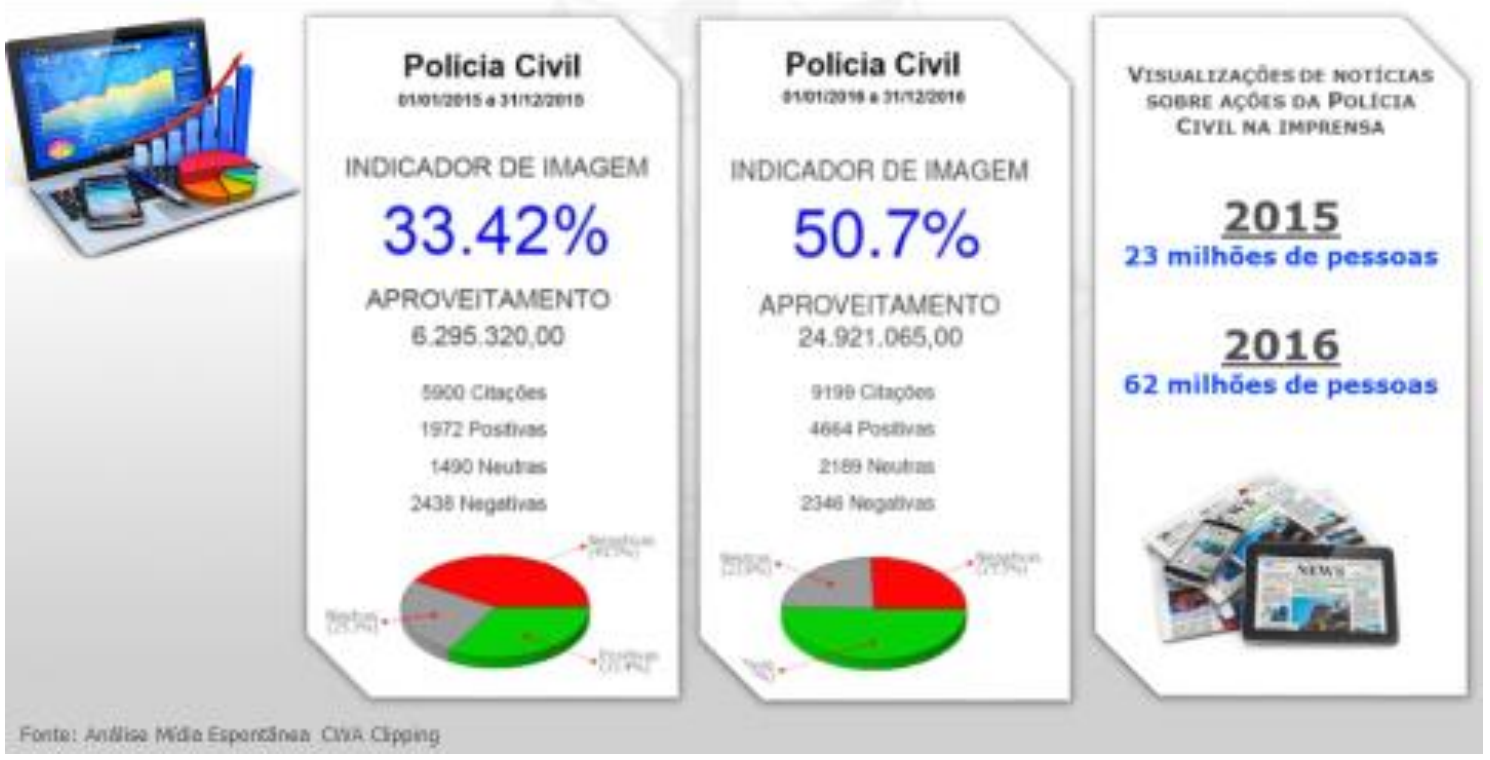

